\title{
Comparison of microwave drying and oven-drying techniques for moisture determination of three paddy (Oryza sativa L.) varieties
}

\author{
A. M. C. Nirmaan ${ }^{1}$, B. D. Rohitha Prasantha ${ }^{1,2^{*}}$ and B. L. Peiris ${ }^{1,3}$
}

\begin{abstract}
Background: The standard method for grain moisture measurement is the conventional air oven-drying technique. This method requires a longer period of time to determine the moisture content (m.c.). Although electric moisture meters are popular in rice industries, it has to be calibrated frequently with the oven-drying method. Therefore, an alternative but fast and reliable method is required, especially, for the grain marketing industries.

Results: Three different sizes of paddy (Oryza sativa L.) samples (Bg 300-intermediate bold, Bg 358-short round and At 405 -long slender) were used for this study. Five different moisture levels (12-20\% wet basis) were prepared by adding known amounts of water. Relationship between the microwave oven and hot air oven moisture values were evaluated using Pearson, Spearman and Kendall correlation coefficient methods. The linear regression relationship was also established between hot air oven and microwave oven moisture determination methods. According to the data, except for $870 \mathrm{~W}$ of absorbed MW power setting level, the other two MW power setting ( $265 \mathrm{~W}$ and $550 \mathrm{~W}$ ) showed a significant statistical correlation $(r>0.55, P<0.01)$ between the air oven and MW oven m.c. values of the three paddy samples. However, MW settings of $550 \mathrm{~W}$ for $7 \mathrm{~min}$ of absorbed power indicated a significantly higher regression coefficient of determination $\left(r^{2}=0.94, P<0.01\right)$ with air oven m.c. values.
\end{abstract}

Conclusion: From the study, it can be concluded that the domestic microwave oven can be successfully used to determine the moisture content of different paddy varieties as an alternative method to the conventional air ovendrying method.

Keywords: Microwave, Paddy, Moisture, Hot air oven, Power

\section{Background}

Moisture content (m.c.) is the most important factor that affects the storage, processing and marketing of rice [7, $10,13]$. Most of the physical, chemical, mechanical and thermal properties of rice are affected due to m.c. which later determines the quality of the raw rice (paddy). Due

\footnotetext{
*Correspondence: rop_bd@yahoo.com

${ }^{1}$ Postgraduate Institute of Agriculture, University of Peradeniya, Peradeniya 20400, Sri Lanka

Full list of author information is available at the end of the article
}

to frequent fluctuation of relative humidity (r.h.) rather than the temperature in the tropics, m.c of the stored paddy and rice should be checked on a periodic time scale. Rice m.c. is independent of the quantity or shape of the materials [19], but it is the most suitable parameter for harvesting, storage, processing, transport and price determination in the market $[10,11,18]$. At the time of paddy harvest, m.c. is about $20 \%$ (wet basis), but harvested paddy must be dried to $12 \%$ m.c. (w.b.) for safe storage [4]. If paddy is harvested at a higher m.c. $>20 \%$ (w.b.), it may cause mechanical damage to the paddy 
kernels during the mechanical harvesting process. As a result of that grains can be infected by fungi and insects. If the m.c. of storage rice/paddy is higher than the storage environment, then microorganisms and insects can spoil the cereal grains making them unsuitable for human and animal consumption. Rice is unique among other cereal grains because it is consumed primarily as whole grains. Therefore, high breakage of rice grains during milling caused significant loss to the rice quality and their market value. Non-uniform moisture distribution is often found in rice storage; therefore, sampling and moisture determination is an important operation to control postharvest loss of grains $[6,10]$.

The standard method for grain moisture measurement is the conventional air oven-drying technique $[8,16]$. Several standard temperature-time combinations that are being used for these ovens such are 100$102{ }^{\circ} \mathrm{C}$ for $16-18 \mathrm{~h}, 100-110{ }^{\circ} \mathrm{C}$ for $14 \mathrm{~h}$ and $130{ }^{\circ} \mathrm{C}$ for $2 \mathrm{~h}[2,12]$. The standard conventional air oven method requires a longer period of time to determine the m.c. [13]. Although electric moisture meters are popular in rice industries, it has to be calibrated frequently with the oven-drying method. Therefore, an alternative but fast and reliable method is required, especially, for the grain marketing industries $[6,18,20]$. It has been found that direct relationship exists between the m.c. and dielectric properties of grain moisture content $[3,10]$.

Microwave heating (MW) applications have been well known for a long time, and have many potential applications such as grain moisture determination, drying, disinfestation, heating, blanching, extraction, cooking, etc., $[15,21]$. Microwave oven considerably saves time, utilizes less space, and requires approximately $25 \%$ less energy than the conventional air oven [5]. Although the initial cost of a MW oven is higher than the conventional air oven, the operational cost is low compared to the air oven method. Therefore, the domestic microwave oven has enormous potential use to determine the m.c. of many cereals within a short period of time under lower cost. Therefore, the objective of this study is to compare the effectiveness of conventional air oven-drying method and a domestic microwave oven method to determine the moisture content of rice.

\section{Methods}

\section{Paddy samples preparation}

The paddy or rough rice (O. sativa L.) varieties Bg 300, Bg 358 and At 405 were obtained from the Research and Development Institute, Sri Lanka. Paddy samples were collected at the harvest maturity (Table 1) and sun dried up to about $12 \pm 1 \%$ wet basis (w.b.) of moisture content. Experiments were conducted for the combinations of five different moisture levels which were $12 \%, 14 \%, 16 \%, 18 \%$,
Table 1 Paddy varieties according to their grain type, maturity and moisture content at the harvesting stage

\begin{tabular}{|c|c|c|c|c|}
\hline Paddy variety & Grain type & $\begin{array}{l}\text { Common } \\
\text { rice name }\end{array}$ & $\begin{array}{l}\text { Maturity } \\
\text { stage } \\
\text { (days) }\end{array}$ & $\begin{array}{l}\text { Moisture } \\
\text { content } \\
\text { (w.b.\%) }\end{array}$ \\
\hline $\mathrm{Bg} 300$ & $\begin{array}{l}\text { Intermediate } \\
\text { bold }\end{array}$ & Nadu & 90 & $21.0 \pm 1.5$ \\
\hline Bg 358 & Short round & Samba & 105 & $20.5 \pm 1.2$ \\
\hline At 405 & Long slender & Basmati & 120 & $22.0 \pm 2.1$ \\
\hline
\end{tabular}

and $20 \%$ (w.b.). Initial moisture content of the samples was $11.6 \pm 0.7 \%$ (w.b.) determined by the air oven-drying method. Based on the initial moisture value, different levels of moisture samples (predicted moisture) were prepared by adding the required amount of distilled water. Each sample was placed in an airtight glass bottle and stored at $4{ }^{\circ} \mathrm{C}$ for 4 weeks to attain the equilibrium predicted moisture levels. During the storage period, bottles were regularly shaken to facilitate the even distribution of moisture throughout the paddy samples.

\section{Moisture determination by hot air oven}

Moisture content (m.c.) of the paddy samples was determined by the hot air oven method. The samples were ground using a laboratory mill (Fred Stein Laboratories M-2, USA) and $5 \mathrm{~g}$ of each ground sample was used to determine moisture content. Three ground paddy samples were weighed into moisture cans and then the samples were heated in a forced air oven (SIBATA SPF-600, Japan) at $130{ }^{\circ} \mathrm{C}$ for $2 \mathrm{~h}$ [12]. Wet basis moisture content (w.b. \%) was measured using the following equation:

$$
\text { Moisture content }(\mathrm{wb} \%)=\frac{\text { Weight of moisture }(\mathrm{g})}{\text { Weight of paddy smaple }(\mathrm{g})} \times 100
$$

\section{Calibration of microwave oven}

A domestic MW oven (Toshiba ER-SS25) was used to determine the moisture. The oven had a capacity of 251 with a rotating circular glass shelf of diameter $315 \mathrm{~mm}$. According to the instruction of the manufacturer, power consumption and power output of the MW oven were $1450 \mathrm{~W}$ and $900 \mathrm{~W}$, respectively. At $100 \% \mathrm{MW}$ output power is equal to $900 \mathrm{~W}$ of heat energy emitted by the MW frequency of $2450 \mathrm{MHz}$. MW oven was calibrated to obtain the absorbed power output levels. A deionized water sample of $200 \mathrm{ml}$ in a $250-\mathrm{ml}$ glass beaker was heated in the microwave oven for $120 \mathrm{~s}$. The temperature rise was measured using a T-type thermocouple and data logger (TC08-PicoTech, UK). A piece of an asbestos sheet (diameter $250 \mathrm{~mm}$; thickness $3 \mathrm{~mm}$ ) was placed on the rotating glass shelf during the heating period to 
prevent the MW shattering and damaging the magnetron [22]. Maximum MW power output for a given sample was determined prior to the experiment. The output, absorbed MW power was calculated $\left(Q / t=m c_{p} \Delta T\right)$ by dividing the energy absorbed by water and beaker during the given the time. The mean values for the absorbed MW powers corresponding to power settings of $300 \mathrm{~W}$, $500 \mathrm{~W}$ and $800 \mathrm{~W}$, were observed as $265 \pm 5,550 \pm 6$, and $870 \pm 15 \mathrm{~W}$, respectively.

\section{Moisture determination by microwave method}

Samples were taken out of the refrigerator and brought to room temperature before moisture determined by the MW oven drying. An individual paddy sample of $5 \mathrm{~g}$ was weighed and spread as thin layer in a 50 - $\mathrm{ml}$ glass Petri dish $(90 \mathrm{~mm} \times 15 \mathrm{~mm})$. The sample was placed on the circular asbestos sheet nearby the center (away from 2 to $3 \mathrm{~cm}$ ) and the sheet was placed on the rotating glass shelf of the microwave oven. The asbestos was used to protect the magnetron and supply the adequate heat from the MW oven, especially when the samples reached low moisture levels during drying [22]. The samples were heated at $265 \mathrm{~W}, 550 \mathrm{~W}$ and $870 \mathrm{~W}$ of absorbed MW power output settings at 20, 7 and $4 \mathrm{~min}$, respectively. Our preliminary trials showed that temperature of the paddy samples rapidly increased and may be burnt under continuous microwave drying at high output power treatments $(>600 \mathrm{~W}$ ) within the first $10-15 \mathrm{~min}$. In order to prevent overheating and non-uniform drying of paddy, prior to the study suitable output power setting levels (power $\times$ time) were selected using paddy sample of $\mathrm{Bg} 358$. Microwave power setting levels were also selected based on the previous studies conducted elsewhere in the world for the moisture determination of cereals $[2,16,23]$. The weight of each paddy sample was determined after MW drying and then the sample was discarded. Prior to obtaining the weight, MW dried paddy sample was stored in a desiccator containing silica gel for about $5 \mathrm{~min}$ at the ambient temperature to decrease the surface moisture and high temperature development in the sample. The weight loss after each MW drying was expressed as the apparent m.c. of the paddy samples. The moisture measurement was stopped and sample was discarded if the paddy sample was burnt (roasted or color change among the grains) during the $\mathrm{MW}$ moisture determination process. All readings were taken in triplicates after discarding the damaged samples. The Petri dish was initially heated in the MW oven for 2 min before using and the same Petri dish was used throughout all the experiments after dry cleaning.

\section{Data analysis}

One-way analysis of variance (ANOVA) was performed for the data obtained from the standard air oven m.c. and apparent MW oven m.c. measurements. Fisher's least significant difference test (LSD) was used for mean comparisons at $P<0.05$. Parametric Pearson correlation coefficient and non-parametric Spearman and Kendall rank correlation coefficient techniques were used to determining the strength of the relationship of moisture contents between the air oven and microwave oven method. General linear model (GLM) was mainly used to establish the nature of relationship between the variables tested under the comparison (7-Ismail and Alyahya [7]). PROC GLM (SAS 9.1) procedure was used to establish a linear model for the determination of moisture by the microwave method. The coefficient of determination of $r^{2}, F$ value, standard error of fit and $P(=0.05)$ values were used to provide the goodness of fit of the data to the straight line.

\section{Results}

\section{Moisture determination}

Initial m.c. of the paddy samples was $11.6 \pm 0.14 \%$ (w.b.). The apparent m.c. $( \pm S D)$ values were obtained after different MW power-time setting levels and air oven drying for each predicted m.c. (Table 2). Air oven method was used as a standard moisture determination method. Compared to the air oven, moisture determination of

Table 2 Mean ( \pm standard deviation) of five apparent moisture contents of three paddy varieties determined by air oven and microwave oven-drying methods

\begin{tabular}{|c|c|c|c|}
\hline \multirow{2}{*}{$\begin{array}{l}\text { Standard mean ( } \pm \text { SD) air oven m.c. } \\
\text { (w.b.\%) }\end{array}$} & \multicolumn{3}{|c|}{ Apparent mean ( \pm SD) MW oven m.c. (w.b.\%) } \\
\hline & $265 \mathrm{~W}$ for $20 \mathrm{~min}$ & $550 \mathrm{~W}$ for $7 \mathrm{~min}$ & $870 \mathrm{~W}$ for $4 \mathrm{~min}$ \\
\hline $12.60 \pm 0.14^{\mathrm{a}^{*}}$ & $12.20 \pm 0.14^{\mathrm{a}^{*}}$ & $12.33 \pm 0.12^{\mathrm{a}^{*}}$ & $13.80 \pm 0.11^{b^{*}}$ \\
\hline $14.67 \pm 0.31^{\mathrm{b}}$ & $12.87 \pm 0.22^{\mathrm{a}}$ & $14.13 \pm 0.22^{b}$ & $16.47 \pm 0.22^{c}$ \\
\hline $17.07 \pm 0.08^{\mathrm{a}}$ & $16.93 \pm 0.22^{\mathrm{a}}$ & $16.87 \pm 0.18^{a}$ & $18.84 \pm 0.21^{b}$ \\
\hline $18.56 \pm 0.64^{b}$ & $15.33 \pm 0.08^{\mathrm{a}}$ & $18.33 \pm 0.12^{b}$ & $20.27 \pm 0.16^{c}$ \\
\hline $19.93 \pm 0.16^{b}$ & $16.47 \pm 0.22^{\mathrm{a}}$ & $20.47 \pm 0.29^{b}$ & $21.87 \pm 0.29^{c}$ \\
\hline
\end{tabular}

* Mean $( \pm$ SD) followed by a common letter within a row are not significantly different $(P>0.05)$ 
three different absorbed MW power-time settings was not uniform.

The results show that there was no statistical difference $(P>0.05)$ of moisture contents between air oven drying and MW oven-drying methods at $550 \mathrm{~W}$ of absorbed MW power output. Average m.c. of paddy samples dried at $870 \mathrm{~W}$ was significantly higher $(P<0.05)$ than that of m.c. obtained by air oven method. Some paddy samples exploded in the process of heating/drying at $870 \mathrm{~W}$ due to the vapor pressure rising rapidly inside the paddy seed. Microwave drying at $275 \mathrm{~W}$ absorbed MW power showed the lowest apparent moisture contents at all five predicted moisture levels compared to the other two MW drying methods. Therefore, MW drying at $550 \mathrm{~W}$ showed more or less similar moisture values $(P>0.05)$ compared to the moisture values of air oven drying for all three paddy varieties.

\section{Correlation between air oven and microwave oven method} Apparent m.c. values obtained from three absorbed MW power levels and air oven moisture data were chosen to establish the relationship between the microwave oven and air oven m.c. determination methods (Fig. 1). Pearson, Spearman, and Kendall correlations were used to evaluate the goodness of fit of the relationship between air oven m.c. and microwave oven m.c. measurements [17]. The parametric Pearson correlation gave the highest $r$-value of 0.92 for air oven and $550 \mathrm{~W}$ of MW ovens drying which established a good linear relationship (Table 3). Non-parametric Spearman and Kendall rank correlations also showed the significantly high correlation $(r>0.55, P<0.01)$ between air oven and MW oven-drying methods. This indicates the high degree of association (Spearman rank) and strength of dependence (Kendall rank) between two drying methods for moisture determination. MW drying at $870 \mathrm{~W}$ of absorbed power (within $4 \mathrm{~min})$ did not show any significant $(P>0.05)$ relationship between the two drying methods. It also has the lowest Pearson, Spearman and Kendall correlations of $r=0.15, r=0.2$ and $r=0.19$, respectively. Although at $265 \mathrm{~W}$ for 20 min exposure absorbed comparatively high MW energy, Spearman and Kendall showed more or less similar rank correlations values $(r>0.55)$ to the $550 \mathrm{~W}$ MW power, but showed comparatively lower Pearson linear correlation $(r=0.70)$ to the $550 \mathrm{~W}$ MW power level. Therefore, the MW oven drying at $550 \mathrm{~W}$ for $7 \mathrm{~min}$ was selected as the best moisture determination energy value alternative to the air oven-drying method.

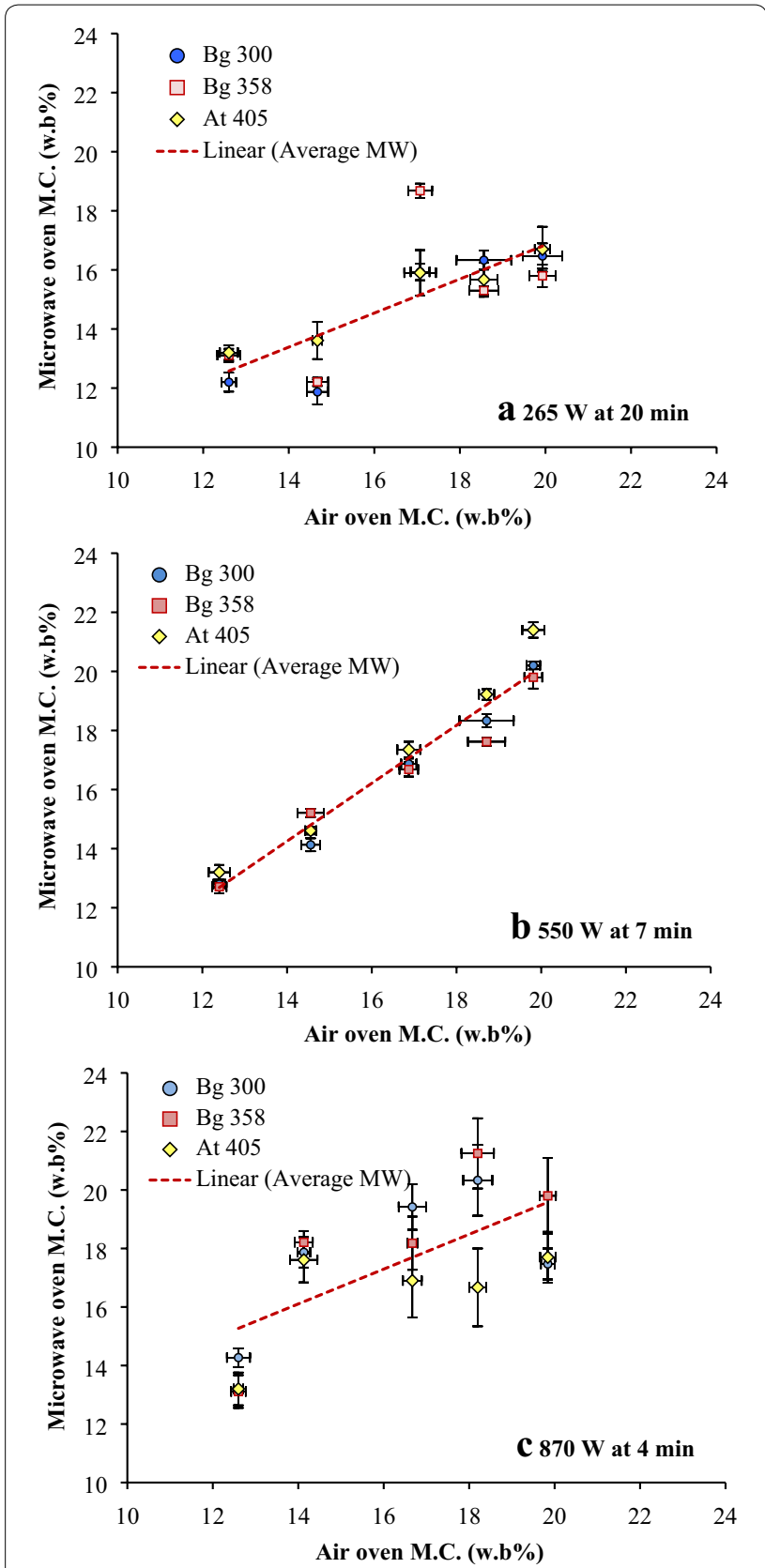

Fig. 1 Apparent moisture contents (w.b.\%) relationship of three different sizes of paddy varieties determine by air oven and domestic microwave oven-drying methods: a $265 \mathrm{~W}$ within 20 min drying, b $550 \mathrm{~W}$ within 7 min drying and c $870 \mathrm{~W}$ within 4 min of absorbed microwave drying

\section{Moisture prediction}

The apparent m.c. content data obtained from the MW oven-drying method $(X)$ and air oven drying moisture values $(Y)$ were fitted to a GLM. All three MW absorbed power setting levels of $265 \mathrm{~W}, 550 \mathrm{~W}$ and $870 \mathrm{~W}$ showed significant $(P<0.05)$ positive relationship 
Table 3 Parametric and non-parametric correlation coefficients between microwave oven and air oven moisture determination methods of the three paddy varieties

\begin{tabular}{llll}
\hline $\begin{array}{l}\text { Absorbed microwave } \\
\text { power }\end{array}$ & Method & $\boldsymbol{r}^{*}$ & $\boldsymbol{P}^{* *}$ \\
\hline 265 W for 20 min & Pearson & 0.70 & 0.001 \\
& Spearman & 0.68 & 0.006 \\
& Kendall & 0.55 & 0.007 \\
550 W for 7 min & Pearson & 0.92 & 0.001 \\
& Spearman & 0.68 & 0.002 \\
870 W for 4 min & Kendall & 0.56 & 0.007 \\
& Pearson & 0.15 & 0.600 \\
& Spearman & 0.20 & 0.483 \\
& Kendall & 0.19 & 0.362 \\
\hline
\end{tabular}

* Correlation coefficient

${ }^{*}$ Probability level

(Table 4). The highest positive coefficient of determination was observed between air oven and MW oven drying at $550 \mathrm{~W}$ of MW power exposure (adjusted $r^{2}=0.94$; $P<0.001)$ for $7 \mathrm{~min}$, but the lowest coefficient of determination value was observed between $\mathrm{MW}$ oven drying at $870 \mathrm{~W}$ for 4 min MW energy exposure and air ovendrying method.

The highest $F_{1,13}$ value of 255.72 and smallest $F_{1,13}$ value of 10.75 was obtained for the absorbed MW power levels of $550 \mathrm{~W}$ and $870 \mathrm{~W}$, respectively. Absorbed MW power level of $265 \mathrm{~W}$ at a longer power exposure time of $20 \mathrm{~min}$ also indicated the comparatively good linear regression fit (adjusted $r^{2}=0.54 ; F_{1,13}=20.25 ; P<0.001$ ) between $\mathrm{MW}$ oven exposure and air oven drying next to the $550 \mathrm{~W}$ of absorbed MW power level.

\section{Discussion}

Generally, domestic MW ovens were not equipped with an airflow system. Therefore, in some instances, a quick charring of the sample was observed. This effect can be attributed to the emission of heat as radiation, which is a result of internal heat generation [2,6]. The results can be affected by non-uniform energy distribution during MW heating/drying. A good deal of trial and error is usually required to avoid common problems of uneven heating, under drying or scorching problem [2]. These results were due to the higher energy absorption of the paddy grains which leads to a sharp increase in grain temperature. Though a rapid increase of temperature results in the higher rate of water removal, it causes an increase in brittleness/roasting of paddy kernels. Therefore, several preliminary studies have been conducted to establish appropriate power setting levels to prevent from non-uniform heat distribution and overheating based on the previous studies [2, 16, 22, 23]. According to Verma and Noomhorm [22], MW heating of grains on a piece of asbestos sheet may help to prevent the paddy samples from overheating and non-uniform power distribution within the samples. The microwave oven operates at room temperature and atmospheric pressure. Therefore, large fluctuation of $\mathrm{RH}$ could have a significant effect on the sample moisture determination [1]. These environmental effects are absent in a conventional air oven method because it is operated at fixed temperature conditions. High water content relates to MW absorption of power, stronger reflection, and shorter wavelengths, which is related to various absorption mechanisms of energy dissipation in the microwaved material $[14,20]$. Low microwave power was used with a longer drying time of food sample. This causes a higher consumption of energy by the sample [24]. Therefore, MW drying at $265 \mathrm{~W}$ for 20 min MW energy absorption showed comparatively lower coefficient of determination (adjusted $r^{2}=0.51$ ) between the two moisture determination methods compared to the $550 \mathrm{~W}$ MW drying. Grain physical and chemical characteristics may change rapidly when they heat for a longer period of time, due to some amount of moisture being tightly entrapped in the starchy kernels [25]. Kaasova et al. [8] found, when high moisture wheat grains were subjected to lengthy MW heating at low absorbed MW power $(298 \mathrm{~W})$ it

Table 4 Predicted linear moisture relationships of air oven and microwave oven drying moisture content (w.b.\%) of the three paddy varieties

\begin{tabular}{|c|c|c|c|c|c|c|}
\hline $\begin{array}{l}\text { Microwave power } \\
\text { (W) }\end{array}$ & $\begin{array}{l}\text { Microwave time } \\
\text { (min) }\end{array}$ & Linear equation* & Adjusted $r^{2}$ & $F$ value & Fit SE ${ }^{\dagger}$ & $P^{* *}$ \\
\hline 265 & 20 & $Y=0.87+1.06 X$ & 0.54 & 20.25 & 1.77 & 0.001 \\
\hline 550 & 7 & $Y=0.28+0.97 X$ & 0.94 & 255.72 & 0.64 & 0.001 \\
\hline 870 & 4 & $Y=3.01+0.76 X$ & 0.36 & 10.75 & 2.09 & 0.01 \\
\hline
\end{tabular}

${ }^{*} Y=$ standard air oven drying m.c. (w.b.\%); $X=$ microwave oven drying m.c. (w.b.\%)

+ Standard error of fit

** Probability level 
significantly changed the physical and chemical characteristics of wheat. Samples exposed to high absorbed MW power rapidly develops a high internal temperature within a short period of time and it becomes very difficult to control the temperature. This effect can be attributed to the uncontrollable final product temperature, which is a consequence of the availability of limited water during the final stages of drying [25]. It causes a rapid increase in the material temperature leading to scorching of the sample [26]. This could be the reason that we observed a poor moisture correlation (Pearson $r=0.15 ; P=0.6$ ) between air oven and microwave oven drying of paddy samples at $870 \mathrm{~W}$ within 4 min of MW energy exposure. Bouraoui et al. [2] reported that a high MW power level (ca. $800 \mathrm{~W}$ ) could cause overestimation of moisture content in some seed samples. This may probably be due to the development of high vapor pressure and restriction of vapor flux flow from inside to outside of the seed. The other reason may relate to the sudden change of physicochemical characteristics of starchy endosperm of the rice $[9,20]$. However, drying at $550 \mathrm{~W}$ of MW absorption power was highly controllable compared to the $265 \mathrm{~W}$ and $870 \mathrm{~W}$ of MW absorption levels. Therefore, at $550 \mathrm{~W}$ of MW absorption showed high correlation (Pearson $r=0.92 ; P=0.001$ ) for moisture between air oven and microwave oven heating. If moisture data can be taken before any large temperature development within the samples, precision of the moisture value may not be significantly affected due to physico-chemical changes or sample scorching. This can be achieved by keeping the heat transfer at low level under controlled MW energy absorption. It was shown that the moisture content of rice decreased linearly with an increase in MW energy (power $\times$ time) consumption and significantly influenced the quality of rice [27]. According to Sharma and Hanna [16], the moisture content of the soybean $>12 \%$ (w.b.) can accurately be predicted using 1.5-min MW drying at $619 \mathrm{~W}$ of absorbed MW power without scorching the seed sample. They found that MW drying time and moisture content determined by the air oven has an exponential relationship. However, the moisture estimation is related to the development of final product temperature within the paddy sample and the amount of vapor diffusion from inside to outside of the paddy samples.

\section{Conclusions}

From the study, it can be concluded that the domestic microwave oven can be successfully used to determine the moisture content of different paddy varieties as an alternative method to the conventional air oven-drying method. The rice processors can use the optimum microwave power-time combination in the routine moisture analyses replacing the time-consuming air oven technique. It can be concluded that $550 \mathrm{~W}$ of absorbed MW power setting at $7 \mathrm{~min}$ is more significant $(P<0.05)$ than any other tested microwave power absorption levels to determine the paddy moisture content between $12-20 \%$ (w.b.).

\section{Abbreviations}

m.c.: moisture content; w.b.: wet basis; MW: microwave; ANOVA: analysis of variance; SD: standard deviation; GLM: general linear mode; LSD: Fisher's least significant difference test; $r$ : correlation coefficient.

\section{Acknowledgements}

Authors wish to the thank Rice Research Institute, Department of Agriculture, Sri Lanka, for providing paddy samples for this study. I would like to extend my gratitude to Prof. R.O. Thattil (Emeritus Professor in Crop Science and Biostatistics) for his valuable support of manuscript corrections.

\section{Authors' contributions}

All authors have equally contributed in the conceptualization and designing of the experiments and preparing the manuscript. AMCN carried out the laboratory studies and BDRP carried out statistical analysis and manuscript preparation and BLP guided the statistical analysis. All authors read and approved the final manuscript.

\section{Funding}

No any research finding received.

Availability of data and materials

All available data are shown in figures and tables.

Ethics approval and consent to participate

Not applicable.

Consent for publication

All authors give their personal consent for publication.

\section{Competing interests}

The authors declare that they have no competing interests.

\section{Author details}

1 Postgraduate Institute of Agriculture, University of Peradeniya, Peradeniya 20400, Sri Lanka. ${ }^{2}$ Department of Food Science \& Technology, Faculty of Agriculture, University of Peradeniya, Peradeniya 20400, Sri Lanka. ${ }^{3}$ Department of Crop Science, Faculty of Agriculture, University of Peradeniya, Peradeniya 20400, Sri Lanka.

Received: 10 July 2019 Accepted: 17 September 2019

Published online: 23 January 2020

\section{References}

1. Beary ES. Comparison of microwave drying and conventional drying techniques for reference materials. Anal Chem. 1988;60(8):742-6.

2. Bouraoui M, Richard P, Fichtal J. A review of moisture content determination in foods using microwave oven drying. Food Res Int. 1993;26(1):49-57.

3. Calay RK, Newborough M, Probert D, Calay PS. Predictive equations for the dielectric properties of foods. Int J Food Sci Technol. 1995;29(6):699-713.

4. Cao W, Nishiyama Y, Koide S. Physicochemical, mechanical and thermal properties of brown rice grain with various moisture contents. Int J Food Sci Technol. 2004;39(9):899-906.

5. Chandrasekaran S, Ramanathan S, BasakT. Microwave food processinga review. Food Res Int. 2013;52(1):243-61. 
6. Digman MF, Conley SP, Lauer JG. Evaluation of a microwave resonator for predicting grain moisture independent of bulk density. Appl Eng Agric. 2012;28(4):611-7.

7. Ismail KM, Alyahya SA. A quick method for measuring date moisture content. Trans ASAE. 2003;46(2):401-5.

8. Kaasova J, Hubackova B, Kadlec P, Prihoda J, Bubnik Z. Chemical and biochemical changes during microwave treatment of wheat. Czech J Food Sci. 2002;20(2):74-8.

9. Kaasova J, Kadlec P, Bubnik Z, Pour V. Microwave treatment of rice. Czech J Food Sci. 2001;19(2):62-6.

10. Kraszewski AW, Trabelsi S, Nelson SO. Simple grain moisture content determination from microwave measurements. Trans ASAE. 1998;41(1):129-34.

11. Lawrence KC, Windham WR, Nelson SO. Wheat moisture determination by 1- to 110-MHz swept-frequency admittance measurements. Trans ASAE. 1998:41(2):135-42.

12. Miah MAK, Haque A, Douglass MP, Clarke B. Parboiling of rice. part i: effect of hot soaking time on quality of milled rice. Int J Food Sci Technol. 2002;37(5):527-37.

13. Nelson SO, Trabelsi S, Kraszewski AW. Advances in sensing grain moisture content by microwave measurements. Trans ASAE. 1998;41(1):483-7.

14. Ryynänen S, Risman PO, Ohlssan T. Hamburger composition and microwave heating uniformity. J Food Sci. 2004;69(7):187-96.

15. Sale AJH. A review of microwave for food processing. Int J Food Sci Technol. 1976;11(4):319-29.

16. Sharma N, Hanna MA. A microwave oven procedure for soybean moisture content determination. Cereal Chem. 1989;66(6):483-5.

17. Thattil RO, Samita S, Gunaratne LHP, Dematawewa CMB, Chandrasiri CWJ. Handbook on design and analysis of experiments. Peradeniya: Postgraduate Institute of Agriculture, University of Peradeniya; 1999. p. 100-123.

18. Trabelsi S, Nelson SO. Calibration methods for nondestructive microwave sensing of moisture content and bulk density of granular materials. Trans ASAE. 2004:47(6):1999-2008.
19. Trabelsi S, Kraszewski AW, Nelson SO. Determining physical properties of grain by microwave permittivity measurements. Trans ASAE. 1999:42(2):531-6.

20. Trabelsi S, Nelson OS, Lewi MA. Microwave nondestructive sensing of moisture content in shelled peanuts independent of bulk density and with temperature compensation. Sens Instrum Food Qual Saf. 2009:3(2):114-21.

21. Venkatesh MS, Raghavan GSV. An overview of microwave processing and dielectric properties of agri-food materials. Biosys Eng. 2004;88(1):1-18.

22. Verma LR, Noomhorm A. Moisture determination by microwave drying. Trans ASAE. 1983;26(3):0935-9.

23. Walde SG, Balaswamy K, Velu V, Rao DG. Microwave drying and grinding characteristics of wheat (Triticum aestivum). J Food Eng. 2002:55(3):271-6.

24. Wang J, Wang JS, Yu Y. Microwave drying characteristics and dried quality of pumpkin. Int J Food Sci Technol. 2007;42(2):148-56.

25. Xu F, Chen Z, Huang M, Li C, Zhou W. Effect of intermittent microwave drying on biophysical characteristics of rice. J Food Process Eng. 2017:40(6):1-13.

26. Zhang M, Tang J, Mujumdar AS, Wang S. Trends in microwave-related drying of fruits and vegetables. Trends Food Sci Technol. 2006:17(10):524-34.

27. Zhao S, Xiong S, Qiu C, Xu Y. Effect of microwaves on rice quality. J Stored Prod Res. 2007:43(4):496-502.

\section{Publisher's Note}

Springer Nature remains neutral with regard to jurisdictional claims in published maps and institutional affiliations.

\section{Submit your manuscript to a SpringerOpen ${ }^{\circ}$ journal and benefit from:}

- Convenient online submission

- Rigorous peer review

- Open access: articles freely available online

- High visibility within the field

- Retaining the copyright to your article

Submit your next manuscript at springeropen.com 